\title{
A Study on the Substitution Efficiency of Agricultural Mechanization Development in Zhejiang Province on Agricultural Labor Force
}

\author{
Chun-Xiang LIU ${ }^{1, a}$, Ningji LV $\mathrm{V}^{1, \mathrm{~b}^{*}}$ \\ ${ }^{1}$ Finance and Trade School, Ningbo University of Finance \& Economics, Zhejiang 315175, China \\ a 171653939@qq.com, b $987490844 @ q q . c o m$
}

Keywords: Agricultural Mechanization, Agricultural "Replacing labor force with Machinery", Substitution Efficiency, Total Agricultural Output Value.

\begin{abstract}
The agricultural "replacing labor force with machinery" is the main content of agricultural mechanization development. In this paper, the empirical analysis of the substitution efficiency of agricultural mechanization development in Zhejiang Province on agricultural labor is conducted. The main conclusions obtained in this paper are: the elastic coefficient of the output of agricultural machinery is 4.1815 , the elastic coefficient of agricultural labor force is -2.3049 , and the semi-elasticity of the agricultural output value to the labor force is 0.0013 , which indicates that in addition to the substitution effect of agricultural machinery on labor force, both of which are mutually complementary. Due to the decline in the quantity of agricultural labor force in Zhejiang, the increase amount in the labor force can be replaced by the agricultural machinery in agricultural mechanization development is relatively reduced. Therefore, the marginal output value of the agricultural labor force in Zhejiang has been increased.
\end{abstract}

\section{Introduction}

Zhejiang is an integrated agricultural region, but it suffers from the aging agricultural population. By the end of 2010, 68.58\% of the population aged 60 and above in Zhejiang Province are the elderly in rural areas, and this would be more severe in 2030 (He Xiaoqin, 2013). In October 2016, with the approval of the Ministry of Agriculture, Zhejiang would build the demonstration province of national agricultural "replacing labor force with machinery". The agricultural "replacing labor force with machinery" is the main content of agricultural mechanization development. Therefore, under the above background, it is of great practical significance to strengthen the macro guidance of agricultural mechanization development in Zhejiang by analyzing the relationship between the development of agricultural mechanization in Zhejiang and the substitution of agricultural labor force. In this paper, the relevant statistical data and calculation methods will be used to estimate the substitution situation of agricultural mechanization in Zhejiang Province for agricultural labor force..

\section{Estimation method of substitution efficiency of agricultural mechanization on labor force}

\subsection{Establishing an analytical function model}

\subsubsection{Transverse selection}

In order to conduct the detailed examination of the substitution relationship between agricultural machinery and agricultural labor force, the transcendental function can be used to analyze the relationship of production function between agricultural machinery, agricultural labor force and agricultural output value:

$$
T V P=A \bullet L^{\alpha_{1}} M^{a_{m}} e^{c+\gamma_{1} L+\gamma_{m} M}
$$

Where: TVP is the total agricultural output value; A is the coefficient, which is referred to as the technical level; L and M stand for the quantity of agricultural labor force and agricultural machinery inputs respectively; $c$ is the partial intercept term; a to $\mathrm{a}_{\mathrm{m}}$ are the output elastic coefficient of the agricultural labor force and the agricultural machinery respectively; $\mathrm{r}_{1}$ to $\mathrm{r}_{\mathrm{m}}$ are the semi-elastic 
coefficient of total agricultural output value to agricultural labor force and agricultural machinery respectively.

\subsubsection{Data acquisition and function fitting}

Function fitting: as equation (1) is a nonlinear function, the natural logarithm is taken on both sides, and then there is

$$
\ln (T V P)=\ln A+c+a_{1} \ln L+a_{m} \ln M+\gamma_{1} L+\gamma_{m} M
$$

Make $\ln \mathrm{A}+\mathrm{c}=a_{0}$ in the formula (2), then there is

$$
\ln (T V P)=a_{0}+a_{1} \ln L+a_{m} \ln M+\gamma_{1} L+\gamma_{m} M
$$

Therefore, the regression equation can be set as:

$\ln (T V P)_{t}=a_{0}+a_{1} \ln L_{t}+a_{m} \ln M_{t}+\gamma_{1} L_{t}+\gamma_{m} M_{t}+u_{t}$

Where $t$ represents the year and $u$ represents the residual term. After converting the nonlinear transcendental production function into a linear function by the variable substitution, the multiple linear regression method can be used to determine the output elastic coefficient and the semi-elastic coefficient in the formula (4).

\subsection{Calculation of the marginal technological substitution rate of agricultural machinery to agricultural labor force}

The substitution relation of agricultural machinery to agricultural labor force can be expressed by marginal technology. By finding the derivative of $\mathrm{L}$ in the formula (1), and the derivative of $\mathrm{M}$ of the formula (1), and the differential is substituted by difference to obtain:

$$
\frac{\Delta L}{\Delta M}=\frac{L\left(a_{m}+\gamma_{m} M\right)}{M\left(a_{1}+\gamma_{1} L\right)}
$$

According to the definition of the related substitution rate of marginal technology, the calculation formula of marginal technology substitution rate of agricultural machinery to agricultural labor force is as follows:

M R T S $\mathrm{ml}_{1}=-\frac{\Delta L}{\Delta M}=-\frac{L\left(a_{m}+\gamma_{m} M\right)}{M\left(a_{1}+\gamma_{1} L\right)}$

\section{Estimation of the substitution efficiency of agricultural mechanization in Zhejiang province for the marginal technology of transfer of labor force}

\subsection{Establishing transcendence function of agricultural production}

\subsubsection{Data acquisition}

Based on the reference to the Statistical Yearbook of Zhejiang Province and Statistical Statement on Agricultural Mechanization Management, the statistical data such as total agricultural output value, total power of agricultural machinery and agricultural labor force can be obtained.

3.1.2 Function fitting

According to the above method, the regression analysis of the equation (4) is conducted by using the obtained correlation data, and the result is shown in Table 1.

Table 1. Regression results of equation (4)

\begin{tabular}{ccccc}
\hline Variable & Coefficient & Standard Deviation & Value t & Value F \\
\hline $\mathrm{a}_{0}$ & $-7.0227^{*}$ & 5.6050 & -1.2529 & $277.2981^{* * *}$ \\
\hline $\ln \mathrm{L}$ & $-2.3049^{* * *}$ & 1.0617 & -2.1710 & \\
\hline $\ln \mathrm{M}$ & $4.1815^{* * *}$ & 1.1419 & 3.6618 & \\
\hline $\mathrm{L}$ & $0.0013^{*}$ & 0.0011 & 1.1775 & \\
\hline $\mathrm{M}$ & $-0.0016^{* * *}$ & 0.0009 & -1.7831 & \\
\hline
\end{tabular}




$\mathrm{R}^{2} \quad 0.9789$

Note: $* * * * *$ and $*$ represent the significance level of $5 \%, 10 \%$, and $15 \%$, respectively.

The following fitting function can be obtained:

$\ln (T V P)=-7.0227-2.3049 \ln L+4.1815 \ln M+0.0013 L-0.0016 M$

Convert the formula (7) into a non-linear equation to obtain

$$
\text { TVP }=L^{-2.3049} M^{4.1815} e^{-7.0227+0.0013 L-0.0016 M}
$$

Formula (8) is the regression model of the transcendental function of agricultural production of Zhejiang Province from 1986 to 2016.

\subsection{Calculating the substitution rate of marginal technology}

Substituting the above values of $\mathrm{a}_{1}, \mathrm{a}_{\mathrm{m}}, \gamma_{1}, \gamma_{m}$ into equation (6), then equation (6) is converted into

$$
\text { MRTS }{ }_{m 1}=-\frac{L(4.1815-0.0016 \quad M)}{M(-2.3049+0.0013 L)}
$$

Formula (9) is the formula for calculating the substitution rate of agricultural machinery in Zhej iang province for agricultural labor force from 1986 to 2016. Then, after finding the relevant da ta, the substitution rate of marginal technology of agricultural machinery in Zhejiang province for agricultural labor force from 1986 to 2016 can be calculated, which is as shown in Table 2.

Table 2. Substitution rate of marginal technology of agricultural machinery in Zhejiang province for labor force

\begin{tabular}{cccccccc}
\hline Year & MRTS $_{\mathrm{ml}}$ & Year & MRTS $_{\mathrm{ml}}$ & Year & MRTS $_{\mathrm{ml}}$ & Year & MRTS $_{\mathrm{ml}}$ \\
\hline 1986 & 5.9270 & 1994 & 1.8603 & 2002 & 0.3701 & 2010 & 0.0306 \\
\hline 1987 & 5.0886 & 1995 & 1.3352 & 2003 & 0.3358 & 2011 & 0.0184 \\
\hline 1988 & 4.3294 & 1996 & 1.1282 & 2004 & 0.3112 & 2012 & 0.0063 \\
\hline 1989 & 4.5269 & 1997 & 1.0377 & 2005 & 0.2336 & 2013 & 0.0354 \\
\hline 1990 & 4.3325 & 1998 & 0.9169 & 2006 & 0.1212 & 2014 & 0.0430 \\
\hline 1991 & 4.1678 & 1999 & 0.6803 & 2007 & 0.0943 & 2015 & 0.0389 \\
\hline 1993 & 3.5380 & 2000 & 0.5161 & 2008 & 0.0897 & 2016 & 0.0373 \\
\hline
\end{tabular}

It can be seen from Table 2 that, the substitution rate of marginal technology of agricultural machinery in Zhejiang province for agricultural labor force from 1986 to 2016 generally showed a downward trend.

\section{Results and Analysis}

1) Regression statistical analysis of input factors of agricultural production. The value $F$ of the regression model was 272.2981 , and the significance level was significant at $5 \%$, indicating that the overall regression effect of the model was very good. The elastic coefficient of agricultural machinery output was $4.1815 \%$ The output elastic coefficient of agricultural labor force was -2.3049 . The semi-elasticity of the total agricultural output value to the labor force was 0.0013 , that is, for the increase of 10,000 people of agricultural labor force, the total agricultural output value will be increased by $0.13 \%$. The total agricultural output value has a semi-elasticity of -0.0016 for agricultural machinery, that is, for the increase of $10,000 \mathrm{~kW}$ in the total power of agricultural machinery, and the total output value of agricultural machinery will be decreased by $0.16 \%$.

2) The influence of agricultural labor force transfer on marginal rate of technical substitution. Due to the decline of agricultural labor force, the increased labor force that can be replaced by the 
agricultural machinery is relatively reduced, and the marginal output value of agricultural labor force is increased. According to the above economic principle, even if the marginal output value of the agricultural machinery input is not reduced, the marginal rate of substitution will be also inevitably reduced. This is one of the main reasons for the decline of the technical substitution rate of agricultural mechanization development to the labor force in Zhejiang Province.

3) The influence of agricultural mechanization development speed on marginal substitution rate. From 1986 to 2014, the average annual growth rate of agricultural machinery in Zhejiang province was $3.67 \%$, and the declining rate of agricultural labor force was $2.76 \%$ in the same period, which indicated that the development speed of agricultural mechanization was higher than that of agricultural labor force to certain extent.

4) The influence of the structure of agricultural machinery on the marginal rate of labor force. At present, the agricultural machinery in Zhejiang is developing from food production machinery and field universal operation machinery. It is not only an objective requirement of the agricultural development today, but an important reason for the increase in the technical marginal substitution rate of agricultural machinery to the labor force since 2013 (see Table 2).

\section{Acknowledgement}

Thanks for the help from the Project of Zhejiang philosophy and social science planning "Study on Benefit Prediction and Promoting Path of Zhejiang Agricultural Machine's Substitution of Man" (No. 18NDJC009Z).

\section{References}

[1] Jiang Zelin. The role of mechanization in the structural reform of the agricultural supply side. Problems of Agricultural Economy, vol.3, pp.4-8, 2018.

[2] Niu Hang. Research on the role of agricultural mechanization technology in food production and promotion and dissemination strategy. Master's thesis of Zhejiang University, 2016.

[3] Bai Xuefeng et al. Research of the Present Situation and Development Model of China Agricultural Mechanization. Journal of Agricultural Mechanization Research, vol.10, pp.256-262, 2017.

[4] Gu Yikang. The innovative path of structural reform of agricultural supply side in Zhejiang Province. Zhejiang Economy, vol.6, pp.10-11, 2016.

[5] Chen Liancheng. Analysis of Agricultural Mechanization Development in Developed Countries and Area. Problems of Agricultural Economy, vol.4, pp.61-62, 2001.

[6] Qian Wenrong, Ying Yixiao. Analysis of farmers' willingness to participate in rural public infrastructure supply and its influencing factors. Chinese Rural Economy, vol.11, pp.39-51, 2014.

[7] Qiu Ye. The road selection and realization mechanism of small-scale land agricultural mechanization -- Analysis of the grassroots endogenous machinery service market. Problems of Agricultural Economy, vol.2, pp.55-64, 2017.

[8] He Xiaoqin. A Study on the Aging of Agriculture Labor Force: Based on the Investigation of Zhejiang Rural Areas. Population and Economy, vol.3, pp.69-77, 2013. 